\title{
RENAL RICKETS ASSOCIATED WITH PARATHYROID HYPERPLASIA
}

\author{
BY \\ F. S. LANGMEAD, M.D., F.R.C.P., \\ AND \\ J. W. ORR, M.D., B.Sc. \\ (From St. Mary's Hospital, London.)
}

The clinical picture presented by cases of renal dwarfism is well recognized, but there remains some uncertainty concerning the bony changes which form part of it. Those composing so-called renal rickets, though not invariable, are usually obvious and often provide the features which bring the patients under medical observation. Though prominent they are not distinctive enough to secure agreement as to their causation and vary in different cases both in their radiographic and in their post-mortem appearances.

Thus L. G. Parsons ${ }^{1}$ recognizes three forms radiographically:-(1) an atrophic form, which is practically identical with that seen in moderately severe cœliac rickets; (2) a florid form resembling that of infantile rickets, which he regards as possibly an earlier stage of the atrophic form; and (3) a woolly, stippled or honeycomb form, which is the most characteristic finding and quite unlike that of infantile rickets. In the last form there is osteoporosis of the shafts, an appearance of subperiosteal erosion and, in severe examples, a thickening and stippling of the bones of the cranial vault indistinguishable radiographically from that seen in Paget's disease. Despite this lack of resemblance Parsons states that he has no doubt that the changes are actually rachitic in nature, and thus agrees with Shipley et alii ${ }^{2}$, who hold the same opinion, though admitting the difierences in histology. Teall ${ }^{3}$ also recognizes radiographically a variety like that of ordinary rickets, and a second corresponding to Parsons' third form. He regards the sub-periosteal eaten-away appearance as the most important diagnostic sign by $\mathrm{X}$-ray examination.

In contradistinction to the views of Parsons and of Shipley and his co-workers, Brockman ${ }^{4}$ emphasizes the distinction between renal and ordinary rickets. In the examination of three fatal cases he found that the shafts were straighi and not curved as in infantile rickets, and ascribed the deformities to separation and displacement of the epiphyses, the solution of continuity and deformity being progressive. The most important distinction histologically was an active absorption of bone by osteoclasts in the region of the growth disc and of the shaft beneath the periosteum, and its replacement by fibrous tissue, exceeding the amount found in rickets. On the other hand Hunter ${ }^{5}$ states that Professor Turnbull has found in a case of renal rickets which he examined the histological sections of the bones in all respects characteristic of rickets.

A consideration of these divergent findings, koth radiographical and histological, leads one to the conclusion that in some cases renal rickets and infantile rickets are similar, but that in others some additional factor produces the special radiographic picture of the woolly, stippled or honeycomb form with osteoporosis and erosion, and the histological changes 
described by Brockman. The case described below suggests that this factor is an excessive activity of the parathyroid glands in an endeavour to maintain the level of the calcium content in the blood, which is known in renal rickets often to be low and even to fall sufficiently to cause tetany.

The present case was a frank example of renal dwarfism with renal rickets, characteristically ending by uræmia, in which after death hyperplastic parathyroid masses were discovered accompanied by osseous changes, compatible with those of ordinary rickets and osteitis fibrosa in combination. The intervention of the parathyroid was suggested by Swart ${ }^{6}$ after his study of a case of renal rickets (1930), but no autopsy was permitted.

\section{Case report.}

We now give the clinical, radiographic, post-mortem and histological reports on our case.

Clinical report.-The boy, aged 14 years, first came under observation in September, 1925, as a typical example of renal infantilism presenting at that stage no bony changes recognizable clinically or by $\mathrm{X}$-ray examination. His appearance and stature resembled that of a boy of 9 or 10, rather than of 14, and the change in his health and failure to grow were dated by his mother from an attack of diphtheria at the age of 5 . He passed up to $154 \mathrm{oz}$. of urine daily, of specific gravity 1004, containing a trace of albumin, but no casts. Polydipsia was a prominent symptom. The cardiac dullness was slightly increased, the aortic second sound accentuated, and the brachial arteries appeared to be slightly hardened. The blood pressure was: systolic $126 \mathrm{~mm}$., diastolic $98 \mathrm{~mm}$. Renal efficiency tests indicated gross defect in renal function, maximum and minimum concentration as estimated by Calvert's test each equalled 0.9 per cent., and the blood urea was $132 \mathrm{mgrm}$. per $100 \mathrm{c.cm}$. Before his discharge one month later the figures were little better, maximum concentration being 0.93 per cent., minimum 0.80 per cent., and blood urea $118 \mathrm{mgrm}$. per $100 \mathrm{c.cm}$. The Wassermann test was negative and no changes were found in the ocular fundi. There were no uræmic symptons.

He did not appear again until July, 1931, 6 years later, when aged 20 years. Despite the previous renal efficiency estimations he stated that he had felt perfectly fit until 6 months previously, and had been working on the stage doing odd jobs that ome his way in connection with a touring company. For about 6 months he had noticed that he became tired on walking, and on examining his legs had found himself. to be knock-kneed. This deformity increased rapidly and on consulting his doctor he was sent back to hospital, still protesting that he was in good health. On questioning him it was elicited that the polyuria and polydipsia had persisted, and that he had suffered from occasional headaches and attacks of epistaxis.

His height at 20 years was $4 \mathrm{ft}$. 6 in. and weight $18 \mathrm{kgrm}$., his complexion sallow, : and nutrition poor; and there was now evident renal rickets, particularly at the knees, with pronounced genu valgum especially on the right side. He could walk only by the aid of a stick. The blood pressure was $119 \mathrm{~mm}$. systolic, $78 \mathrm{~mm}$. diastolic, and the brachial and axillary arteries were now distinctly thickened. There was slight hypertrophy of the left ventricle, the apex-beat being in the 6th space, half an inch outside the mid-clavicular line, and the impulse forcible. The aortic second sound was accentuated. The polyuria had led to definite distension of the bladder, producing a vesical dullness reaching to the umbilicus, which did not disappear on micturition. The urine still contained a trace of albumin and there were a few hyaline casts. The blood urea was $128 \mathrm{mgrm}$. per $100 \mathrm{c.cm}$., maximum and minimum urea concentration were each 0.5 per cent. By Volhard's test, $33 \mathrm{oz}$. of urine were excreted in 7 hours, and the specific gravity fluctuated between 1005 
and 1008. He took his discharge and it is regrettable that no blood chemistry estimations are available.

Ten days later he was readmitted for epistaxis and soon developed uræmia which proved fatal. The urine contained 0.3 per cent. of protein and the blood-urea amounted to $355 \mathrm{mgrm}$. per $100 \mathrm{c.cm}$.

Radiographic report.-Figures 1 to 5 are from the case described, and show the woolly type of change seen in renal rickets. Figures 6 and 7 show a frankly rachitic type from another case, which is mentioned below and is included for the purposes of contrasting the one with the other.

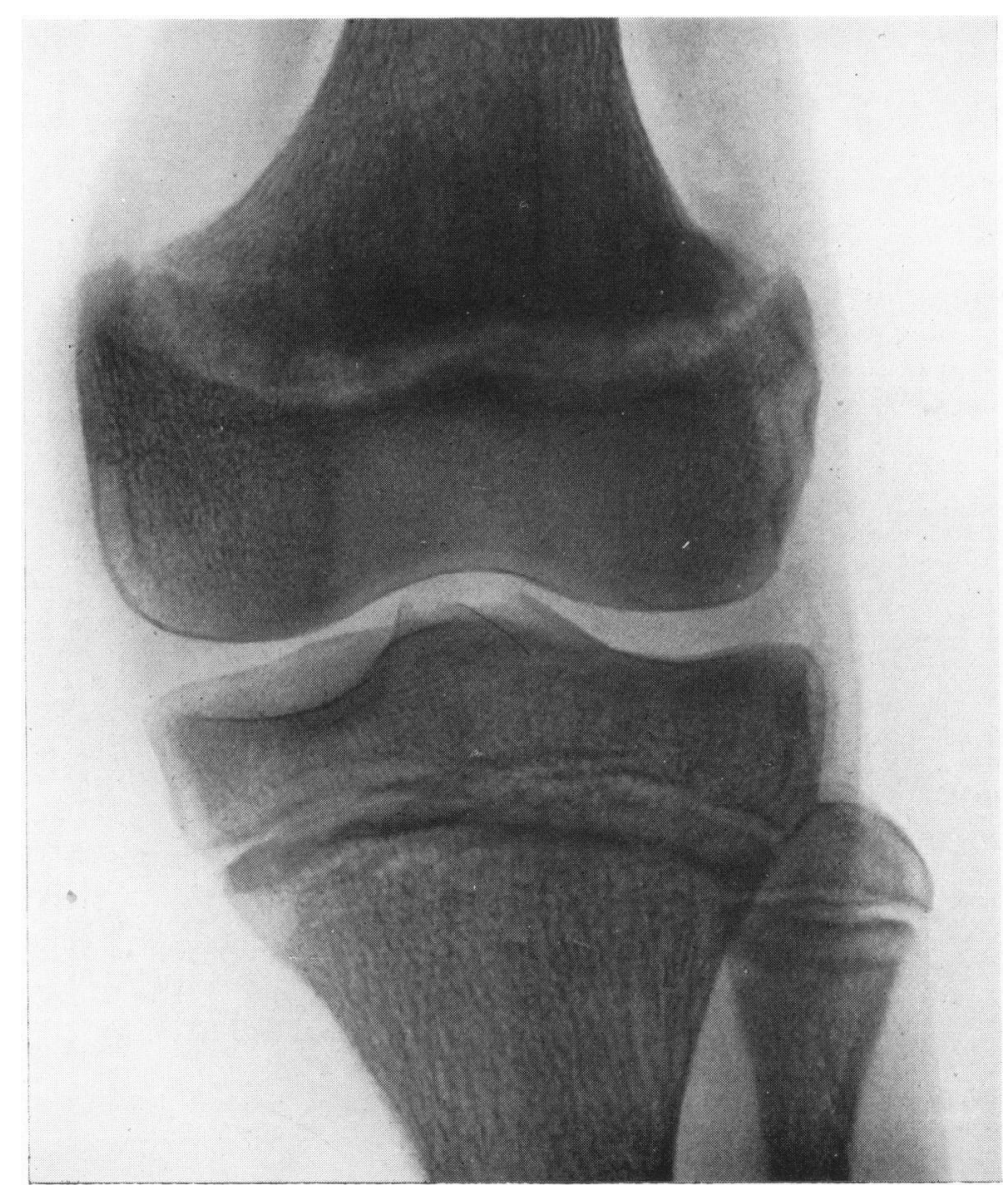

Frti. 1.-Antero-posterior view of the left knee showing the coarse stippled type of osteoporosis, the subperiosteal erosion and the woolly changes at the metaphysis of the lower end of the femur.

The radiographs show both knees, and are the only skiagrams available except for one of the calvarium, which is of the post-mortem specimen.

KNEES.-The bones are small for the age, 20 years, and show marked osteoporosis, which is obvious even in the absence of a radiograph of the normal for comparison. The diaphysis shows a coarse stippling, or honeycomb appearance, and the cortex 
is thinned to a line or series of lines. The epiphysis is ununited, but the most marked changes are to be seen at the metaphysis, and in this case, at the lower ends of the femora. In this region there is erosion of bone beneath the periosteum, making the end of the shaft too small for the epiphysis, and a woolly appearance from which all bone texture is absent; also the metaphyseal aspect of the epiphysis

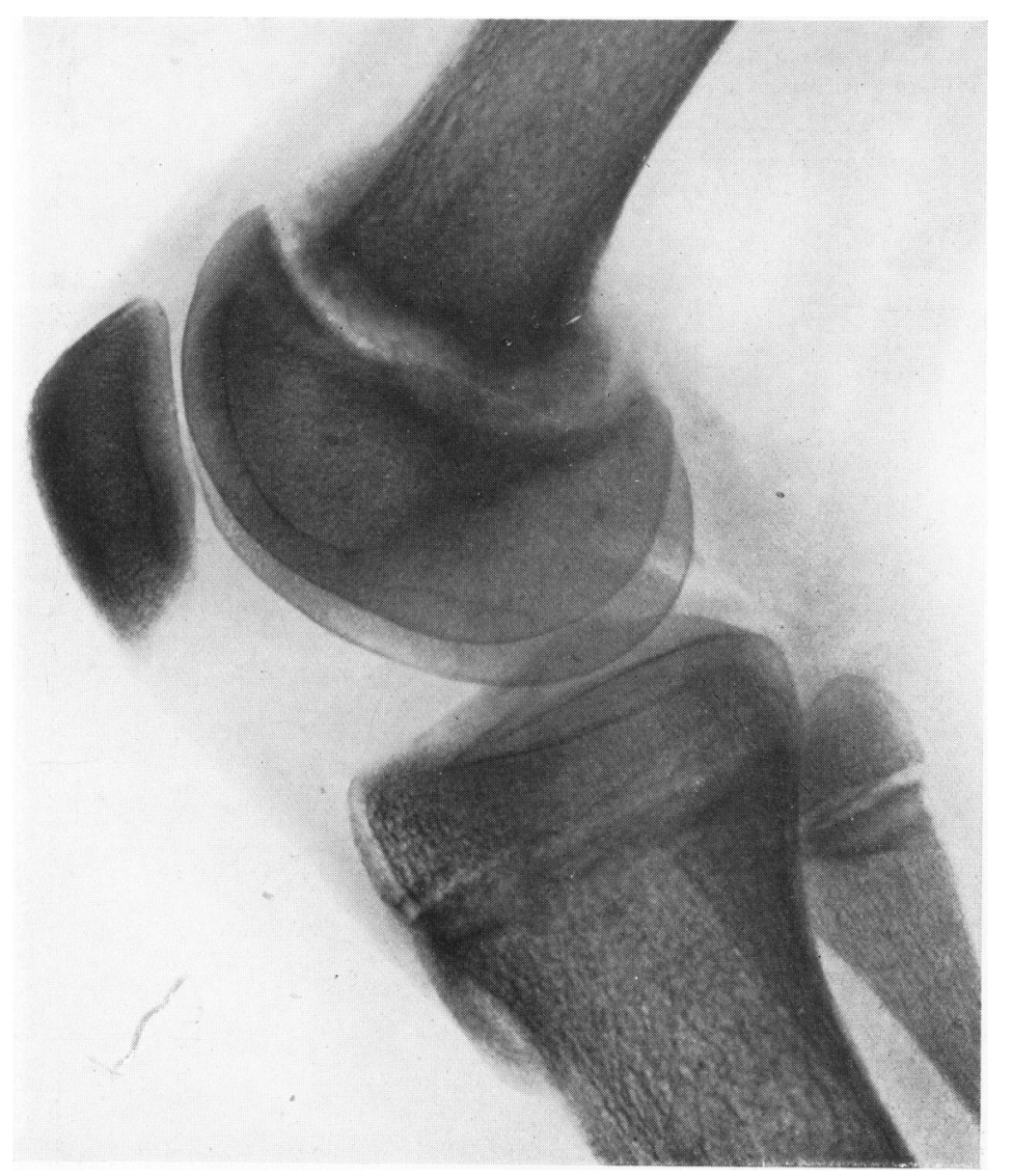

Fici. 2.-The lateral view of the left knee. There are no definite changes at the epiphysis of the upper end of the tibia or the fibula except the wide epiphyseal line.

appears to be slightly more hollowed than the normal. The shafts of the bones are straight, but the right knee shows a deformity at the lower end of the femur, which may be described as a slipped epiphysis. This, of course, may occur; but the typical change is one of progressive displacement and deformity, due to continuous erosion of bone at the metaphysis. The changes tend to be asymmetrical and may be much more marked in one region than another, but the presence of a deformity possibly makes the condition appear less symmetrical than it really is.

Calvarium.-This radiograph was taken of the specimen in a direction which is not possible in the living subject, and so presents an aspect not commonly seen with consequent difficulties in interpretation. 
Osteoporosis, however, is definite and there is very marked coarse stippling, both the outer and inner tables being ill-defined, and no definite diplöe can be made out at the borders. There are five round transradiant areas more or less close to the sagittal suture, but it will be noticed that three of these, the most circular and precisely defined, receive the terminations of undoubted vascular markings; the other two are much more like pathological changes in the bone.

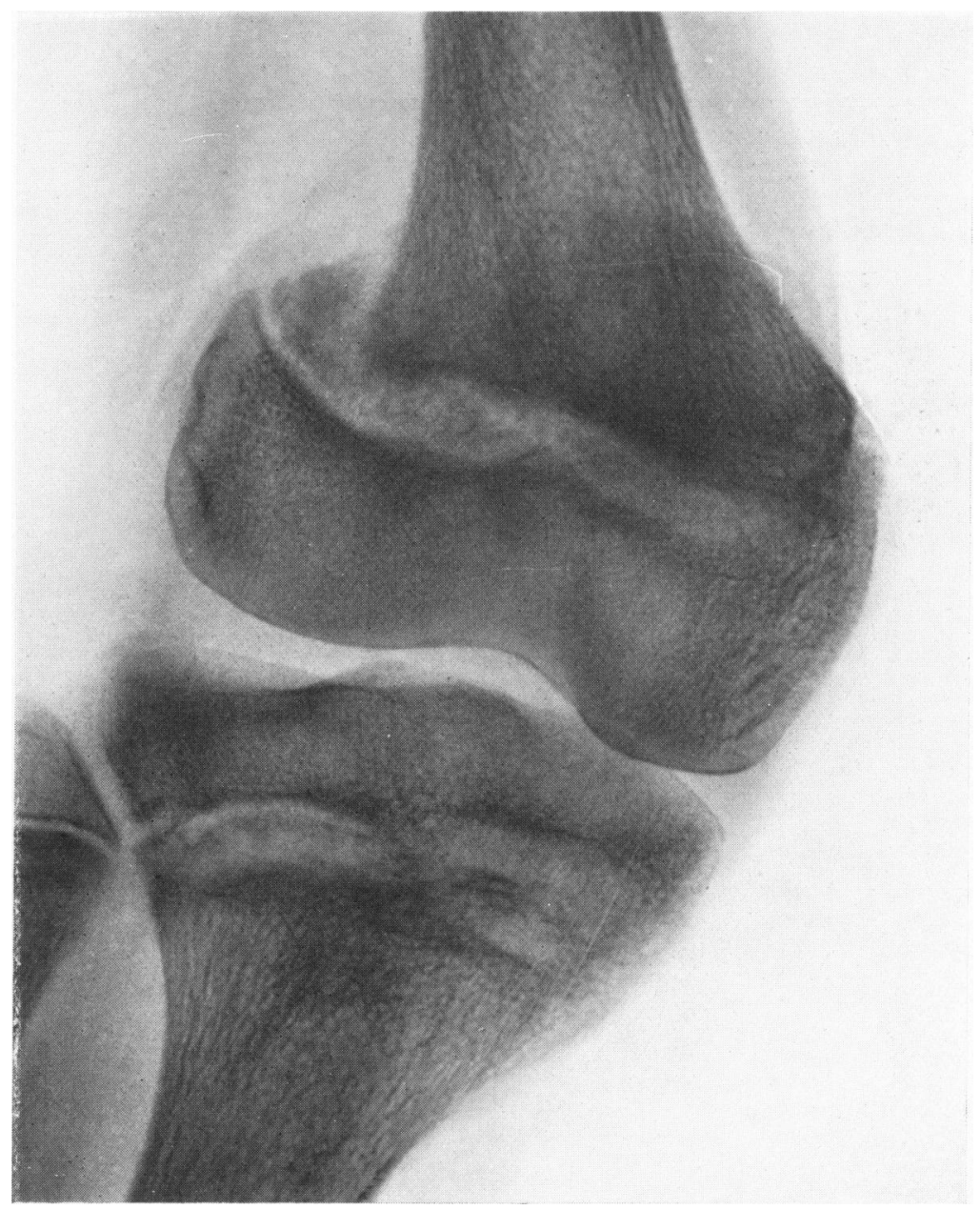

Fit. 3. -Antero-posterior view of the right knee. The changes are more extensive, the erosion is more marked on the inner side and there is a genu valgum deformity.

The changes in the skull may be such as to resemble closely those seen in osteitis fibrosa and Paget's disease. Generalized osteoporosis is present in the frankly rachitic type, but it does not present the same coarse stippled appearance, and it is interesting to note in this connection, that a coarse stippling very like, if not identical with, this is described by Camp and Ochsner ${ }^{7}$ in their radiological study of the bone changes in hyper-parathyroidism associated with parathyroid tumour. They described it as of a miliary granular appearance, and state " that it is best observed in the skull, and that it appears to be peculiar to hyper-parathyroidism.' 
CONTROL CASE.-Figures 6 and 7 are from another case of renal rickets, aged 17 years, and show the appearances seen in the frankly rachitic type. The appearances at the epiphysis are those of infantile rickets on a grand scale. The shaft is splayed out at the epiphysis into the typical champagne glass deformity, the edges beneath the periosteum are serrated and sharply defined, the epiphyseal gap is much wider than that in the woolly type, and the diaphysis appears too big for the size of the epiphysis. The changes are more symmetrical and curvature of the long bones may develop.

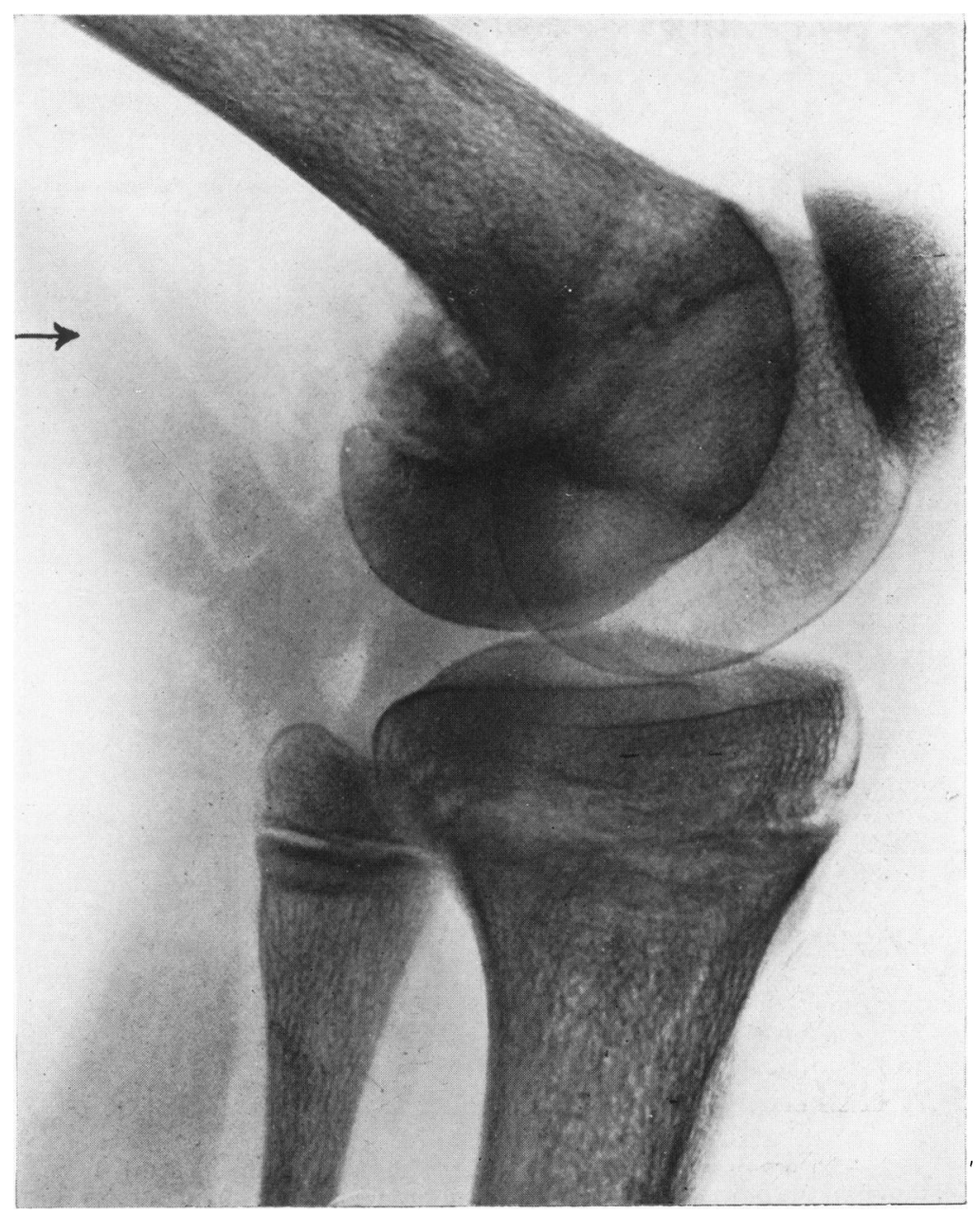

Fig. 4.-Lateral view of the right knee. There are slight but quite definite changes at the upper end of the tibia. The arrow indicates an area which is suggestive of callus.

In the woolly type, the X-ray appearances alone may be considered as pathognomonic of the condition, but a full dossier will be necessary to differentiate the rachitic type from cœliac, recurrent and late rickets. The marked difference in radiographic appearances suggests a different ætiology, or the presence of some modifying factor. 
Post-mortem examination (Sept., 1931, P. M. 215/31).-The general development approximated to that of a boy of 10 years; hair was present, however, on the upper lip and pubes. Body weight $18 \mathrm{kgrm}$., body length $128 \mathrm{~cm}$. Bilateral genu valgum, more marked on right side.

Heart (170 grm.) of typical renal type, with considerable hypertrophy of the ventricle; general hypertrophy of the arteries without atheroma. Slight hypostatic pneumonia at base of left lung. Slight mucous catarrh of stomach; intestines normal, long retro-cæcal appendix extending up to hepatic flexure of colon; parenchymatous degeneration and œdema of liver; gall bladder, bile ducts, and pancreas normal. Spleen normal in size, pale, Malpighian bodies small. Thymus rather œedematous, and persistently glandular. Thyroid normal size, pale, with excess colloid. Adrenals large, with much lipoid in the cortex. Pituitary very small, the apparent separation between the lobes being very near the anterior pole (see histology); rounded swelling $(0.8 \times 0.6 \times 0.8 \mathrm{~cm}$.) at the attachment of the infundibulum to the floor of the third ventricle. Pineal gland possibly slightly enlarged. Brain otherwise normal.

Parathyroids.-Four enlarged parathyroids were found, the largest two $(1.0 \times 0.7 \times 0.45 \mathrm{~cm}$. and $1.5 \times 0.8 \times 0.4 \mathrm{~cm}$.) being in relation to the lower pole of the left lobe of the thyroid, the other two being at the lower pole of the right lobe. All were encapsulated oval bodies with a definitely brownish colour. From the same region were removed diffuse masses resembling fatty tissue, but sinking in water.

KIDNEYs.-Both kidneys were very small (total weight 100 grm., sizes $8 \times 3 \cdot 2 \times$ $1.7 \mathrm{~cm}$. and $6.6 \times 3.3 \times 2 \mathrm{~cm}$.), and typically granular in appearance. The subcapsular surface showed uniformily distributed pale yellow regeneration nodules, alternating with pinkish-grey depressed zones adherent to the capsule. The demarcation between cortex and medulla was poorly marked, the cortex thinned out irregularly and showed a poor pattern with occasional cysts. The arcuate vessels showed hypertrophy but no occlusion of their lumina. Bladder hypertrophied, ureters dilated, prostate and urethra normal. Testes small and resembled infantile type.

Bones.-All the bones were much softer than normal, and it was possible to cut chips off the calvarium and vertebræ with a knife. The costo-chondral junctions were enlarged, and on cross-section showed a ragged widened and congested zone at the line separating bone and cartilage. The lower epiphysis of the right femur was twisted laterally so that the articular surface faced outwards, and the inner condyle consequently appeared to be enlarged. All the epiphyseal cartilages were thickened (lower end $0.7 \mathrm{~cm}$. , great trochanter $/ \mathrm{shaft} 0.2 \mathrm{~cm}$. , head $/ \mathrm{shaft} 0.6 \mathrm{~cm}$.) and irregular; and broad hæmorrhagic zones were present in them, especially in that at the lower end of the shaft, where there was an almost complete transverse division of the cartilage by hæmorrhage. In this hæmorrhagic zone were gritty calcified areas. The cortex of the shaft was thinned, especially at the two ends, and the marrow was fatty in the lowest quarter and the dull brown-red in the remainder of the shaft.

Histological examination. Bones.-Portions were taken from the parietal bone, the costo-chondral junctions, and the shaft and lower end of the femur, and rapidly decalcified in Jenkin's fluid. Similar material was left in Muller's fluid for six months, followed by brief treatment with Jenkin's fluid before embedding, to study the distribution of calcification. Sections were also cut from a costo-chondral junction without any preliminary decalcification to confirm the picture afforded by the Muller sections.

Parietal bone.-All the bony lamellæ are thinned out as the result of lacunar resorption, and on the surface of each is a layer of osteoid tissue, only the central part being calcified. Osteoclasts are present in large number in the lacunæ and in other parts of the marrow spaces. The marrow otherwise consists of fine collagenous fibrils and histiocytes, there being no hæmopoietic elements (Fig. 8). 
Fra. 5.-Calvarium, showing the coarse stippled or miliary granular appearance, and the five transradiant areas. 
Costo-chondral junctions.-The bone-cartilage junction is irregular, and in places there are peninsular processes of cartilage almost cut off from the main mass of cartilage. There is an abnormally wide zone of proliferating cartilage, consisting of irregularly arranged groups of large swollen cells with little matrix. Provisional calcification is poorly marked, being present only in immediate contact with the line

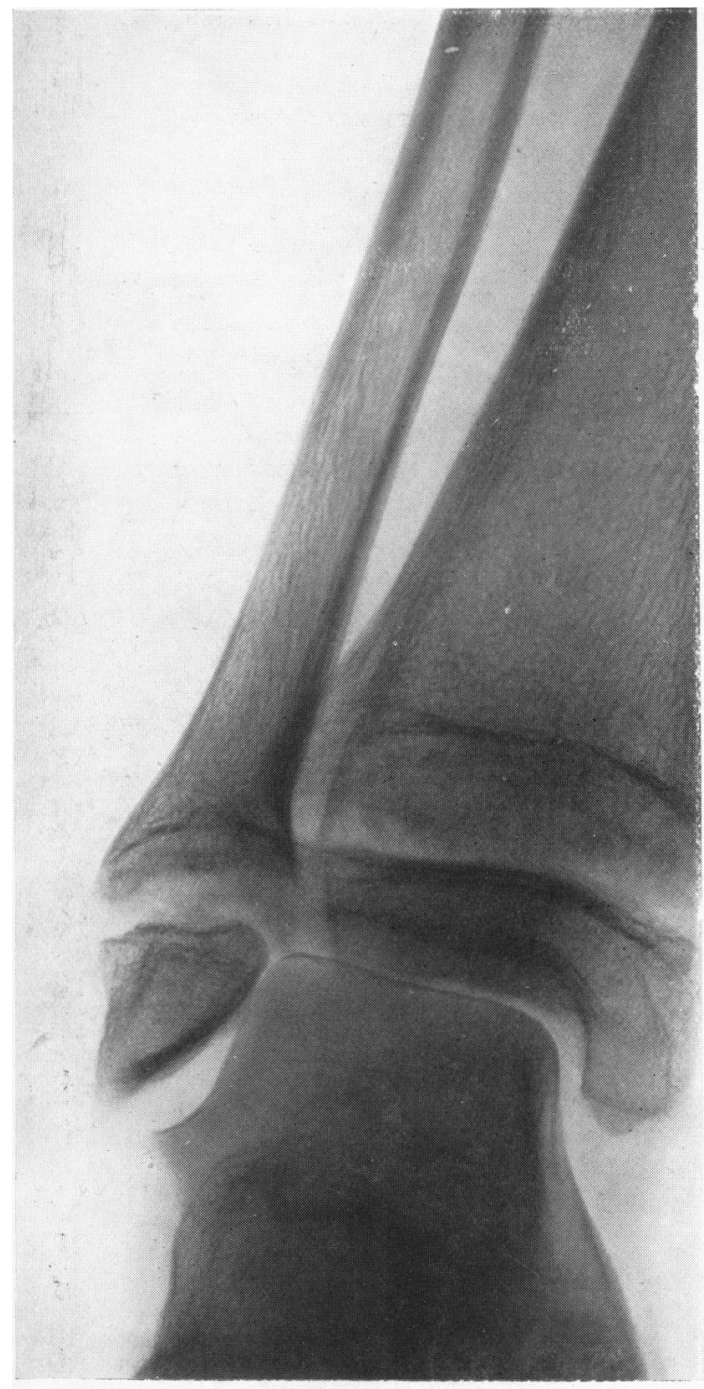

Fig. 6.

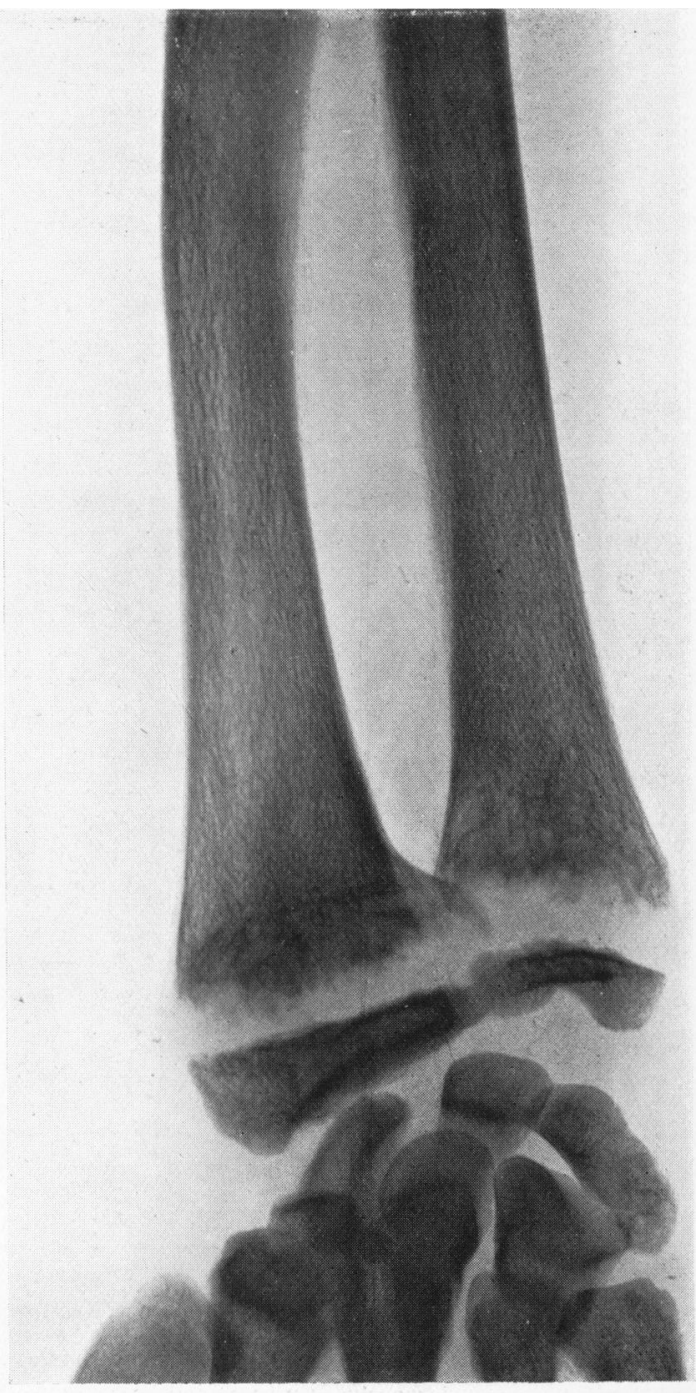

Fif: 7.

Fic. 6 and $7:$ A control case of renal rickets, aged 17 years, showing the frankly rachitic type of change with a wide epiphyseal gap and the champagne-glass appearance at the metaphysis.

of ossification, and even there it is deficient, the line of calcification being broken. Against provisionally calcified cartilage bone is forming in the usual way with a thin intervening line of osteoid tissue (possibly in slightly excessive amount), but apart from these small islands of true bone the first two millimetres from the 
cartilage is represented by fibrous marrow, numerous large active osteoclasts, and coarsely fibred osteoid tissue. The character of the tissues then changes in a rather definite oblique line, and suggests the possibility of these appearances being determined in some degree by a previous fracture. The bone thereafter is lamellar, but the lamellæ are small with numerous lacunæ, and nearly all are covered with a layer of osteoid tissue. The marrow is patchy, partly hæmopoietic and partly finely fibrillar collagen, occasionally fatty, but everywhere contains numerous large activelooking osteoclasts.

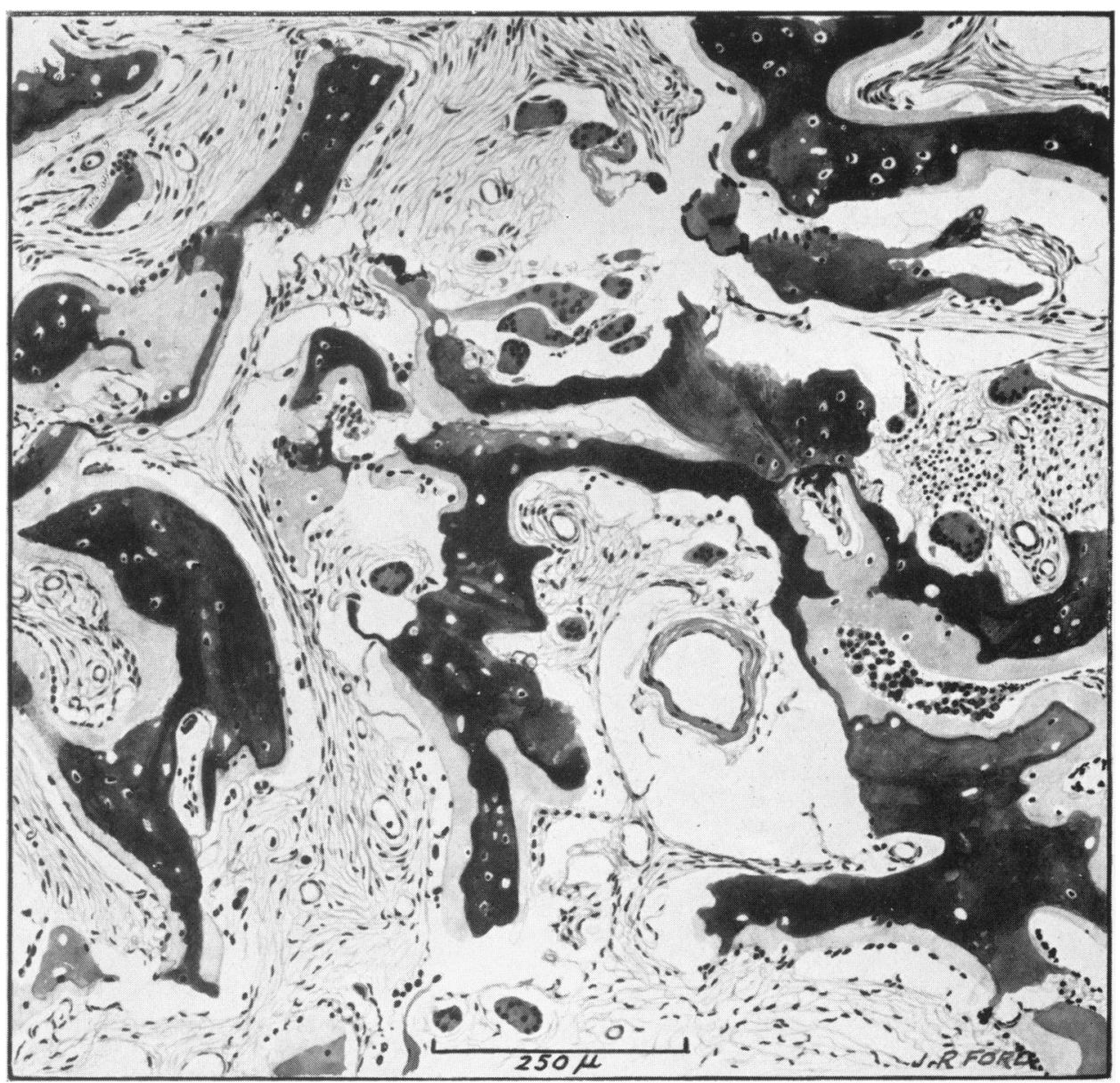

Fr(i. 8. - Transverse section of parietal bone : showing lacunar resorption of bone by osteoclasts, and the fibrous marrow : except where resorption is taking place, the bony lamella are covered with a layer of osteoid tissue.

Lower end of femur.-The epiphyseal cartilage is fractured along the hæmorrhagic line which traverses it, so that it presents four surfaces, metaphyseal, epiphyseal, and one on either side of the fracture. Proliferation is taking place in relation to all of these, with the result that there is no resting cartilage. Provisional calcification is greatest on the epiphyseal surface, where it forms an almost unbroken line; on the metaphyseal surface calcification is patchy as in the ribs; there are a few calcified foci on each fracture surface. The fracture space is filled with red blood corpuscles, with 
numerous proliferating blood vessels; at the edges are collagenous fibrils and histiocytes; and in the centre scattered patches of coarsely fibred osteoid tissue (with slight calcification of the larger masses), the whole resembling callus. The epiphysis shows lamellar bone in small amount next the cartilage, each lamella being surrounded by a thin layer of osteoid tissue. Further back from the cartilage the lamellæ are well formed, and very little osteoid tissue is seen. All the marrow is fatty, and otherwise practically non-cellular. On the metaphyseal side, small lamellæ of bone are related to the calcified parts of the cartilage. Each is covered with a thick layer of osteoid tissue and surrounded by a single row of osteoblasts. Between them is fibro-cellular marrow containing islands of osteoclasts. Further up the bone and in the shaft there is not so much osteoid tissue, but quite a definite layer can still be seen covering each lamella of bone. The marrow is variable in appearance, in places fibrous, in other places fatty with occasional hæmopoietic foci. Where the marrow is fibrous, it is always associated with numerous osteoclasts and lacunar resorption of bone (Fig. 9).

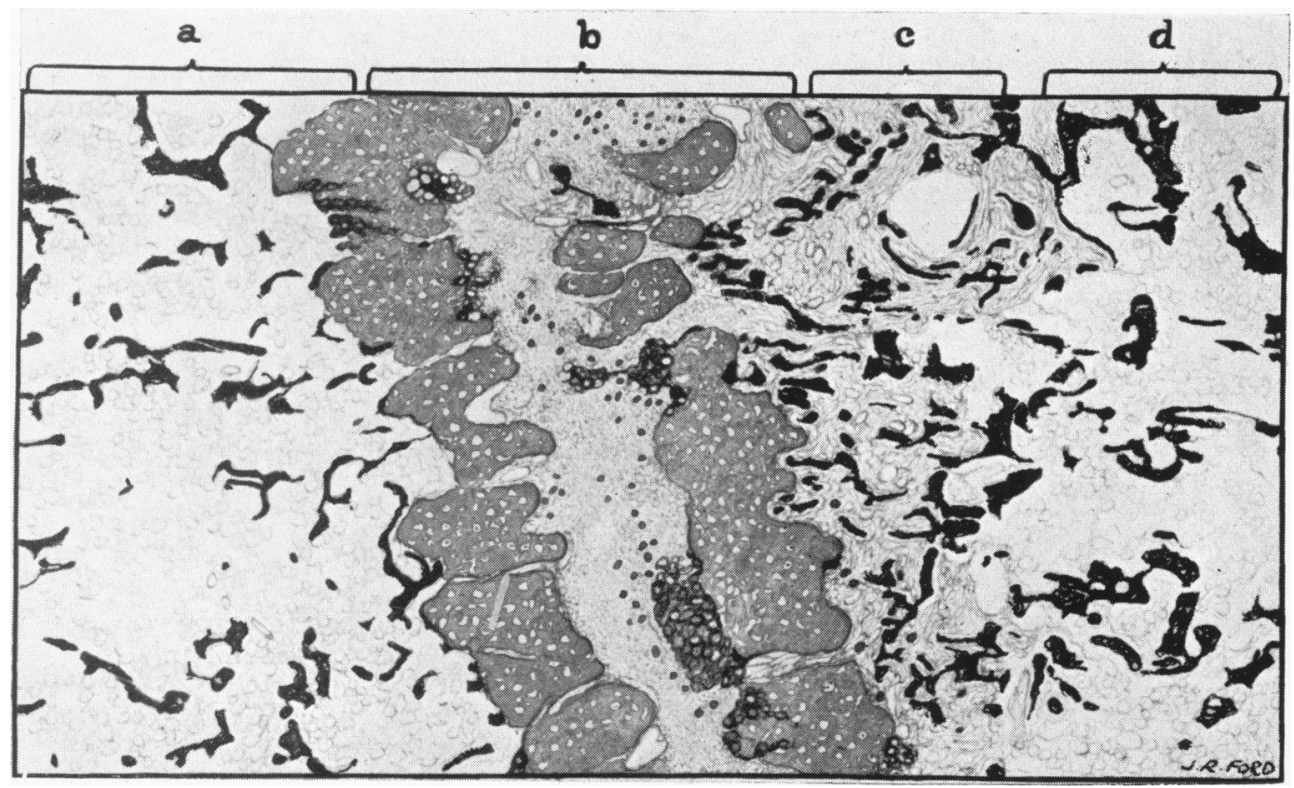

FI(:. 9.-Longitudinal section through epiphyseal cartilage of lower end of femur. $a=$ epiphysis. $b=$ epiphyseal cartilage with hæmorrhage, coarse fibred bone, osteoclasts, etc., occupying the fracture which traverses it. $c=$ metaphysis with fibrous marrow and osteoclasts. $d=$ diaphysis.

KIDnEy.-The glomeruli show hyaline changes, adhesions, necroses, and in many cases complete fibrosis. All the glomeruli seen are affected. No proliferation of Bowman's epithelium is seen. Many of the glomeruli are greatly enlarged, while others are shrunken. Degenerative changes are present in the tubular epithelium. There are numerous large regeneration nodules. The interstitial tissue is the seat of much reticular fibrosis in the form of thick bands of collagen with numerous areas of lymphocytic infiltration. The vessels show hypertrophy with reduplication of their internal elastic laminæ. The histological picture appears to conform to the type described by Russell ${ }^{8}$ as characteristic of renal dwarfism, i.e., nephritis repens, type 3.

Parathyroids. - The large encapsulated mass from the left side consists of parathyroid tissue, not dissimilar to the tumour-like nodules described recently in numerous cases of osteitis fibrosa. It consists of small polygonal cells arranged in 
rounded acini, and intersected in places by bands of fibrous tissue. Very few oxyntic cells are present. It probably represents a functional hyperplasia of the gland. The encapsulated masses from the right side are similar, but conform more closely in appearance to the normal parathyroid. The diffuse masses of tissue removed from the retro-thyroid region consist of odematous fat, fibrous tissue, and lymph glands showing hyperplasia of the sinus endothelium.

Pituitary.-The whole of the bi-lobed structure occupying the sella turcica is composed of anterior lobe tissue, the anterior section consisting mainly of chromophil cells of both types, and the posterior of chromophobe elements. The posterior lobe of the pituitary is represented by the nodule at the base of the infundibulum, which consists of tissue resembling the pars nervosa, covered with a thin layer of pars intermedia tissue.

Other organs.-Pineal gland somewhat enlarged, but structure normal. The suprarenals are large, with much lipoid in the cells of the outer part of the cortex, medullary cells large with darkly staining nuclei. The thymus, is œdematous, showing a proportion of glandular to adipose tissue normal for age; also very large Hassal's corpuscles, consisting mainly of keratin and cell debris. The thyroid vesicles are large and full of colloid, with epithelium flattened. The pancreas shows numerous well formed islets of Langerhans. In the tests spermatogenesis is not well marked, only in a few tubules. There are very few interstitial cells. The prostrate is normal; the unstriated muscle of the gland fuses with voluntary muscle fibres running in from outside. The bladder shows hypertrophy. The lungs, liver, and spleen are normal. The myocardium (left ventricle), aorta, and femoral artery show typical hypertrophy.

\section{Discussion.}

Bone histology. - The bone changes in renal infantilism are inconstant. In many cases, as is well known, there are no skeletal atnormalities at all except the general osseous under-development proportionate to the size and stature of the subject. In a second group of cases, deformities and bony changes occur, and as mentioned above, Hunter" reports that Turnbull has demonstrated the bony changes of true rickets in such cases. The present case, which has many histological points of resemblance to that recorded by Brockman $^{4}$, cannot be so classified, as although some of the appearances are strongly reminiscent of rickets, other changes are present which are not typical of the latter condition. Of these, the chief are the great osteoclastic activity and lacunar resorption of the bony lamellæ. In sections of true rickets which have been compared with the present sections, osteoclasts are present in appreciable number only in the subperiosteal part of the bone. Osteoid tissue is found in both conditions, but in much greater amount in true rickets. In rickets, the marrow displays more hæmopoiesis, kut this may be due to the difference in age. Provisional calcification of the cartilages is limited in the present case to the immediate neighbourhood of the epiphyseal line, whereas in the case of rickets calcified foci are also found some little way back from it; the total amount of provisional calcification is, however, about equal in the two conditions. Fractures of the epiphyseal cartilages were not seen in the true rickets sections.

The lacunar resorption of bone, large number of osteoclasts, and fibrous marrow of the shafts of the long bones and skull bones conform very closely to the appearances in osteitis fibrosa, and in this connection interest attaches 
to the multiple endocrine changes, in particular the hyperplastic parathyroid bodies. The bony changes as a whole may be regarded as a composite picture of osteitis fibrosa and true rickets.

Parathyroid factor. - [t is recognized that parathyroid hyperplasia, with or without adenomata, is closely associated with gross osseous defects, in some of which it is generally regarded as preceding the bony changes whilst in others it is secondary. The surest example of parathyroid overfunctioning as the cause of bone disease is generalized osteitis fibrosa for, as Hunter ${ }^{9}$ points out, in this disease hypertrophy or tumour formation is almost always confined to one parathyroid, the others remaining normal. However, it must ke remembered that Erdheim ${ }^{10}$, who described three cases of parathyroid enlargement in association with osteomalacia, held the view that the skeletal changes precede those of the parathyroid; and Hoffheintz' who collected 45 cases of measurable enlargement of one or more parathyroids, in 27 of which there was definite bone disease, found that whilst 17 were of generalized osteitis fibrosa, there were 8 of osteomalacia and 2 of rickets. Parathyroid hyperplasia has also been met in connection with experimental rickets in rats, in association with want of sunlight, with a deficiency of calcium ingestion and even with carcinomatous infiltration in bone $^{12}$, and in multiple myelomata ${ }^{13}$. Pappenheimer and Minor ${ }^{14}$ have described parathyroid hyperplasia in rickets in children, and Linder and $\operatorname{Vadas}^{1.5}$ record a case of its association with late rickets in a boy of 15 years.

Despite the satisfactory results obtained by removal of the parathyroid tumours in generalized osteitis fibrosa, Barr and Bulger ${ }^{16}$ hold that there is a case for regarding the bone changes as primary even in that disease. Hilding Bergstrand ${ }^{17}$ believes that the histological changes in the bones in cases of generalized osteitis fibrosa are not peculiar, and that a similar picture occurs in physiological lacunar resorption and in many other various pathological conditions. He exemplifies this by illustrations of pathologically increased bone resorption in cases of ' chronic glomerulo-nephritis' with or without parathyroid enlargements, and describes a case in which the kony changes were slight but there were two hyperplastic parathyroid swellings, each the size of a plum, in a patient in whom chronic nephritis was also present.

Another example of parathyroid enlargement in association with renal disease is recorded by Harbitz ${ }^{18}$ in which adenoma of a parathyroid gland accompanied 'chronic interstitial nephritis.' The patient had brittle osteoporotic bones containing many smooth-walled cysts. The bones were soft, readily fractured, and could be cut easily. MacCallum ${ }^{19}$ describes a case where parathyroid adenoma occurred in a young man who died from uræmia due to ' chronic interstitial nephritis,' but in which no mention is made of bony changes.

A study of the literature would suggest that while parathyroid hyperplasia and adenomata are probably primary in true cases of generalized 
osteitis fibrosa, they may occur as secondary developments in other diseases of bone and in various other states including rickets and chronic nephritis. It appears, therefore, that the discovery of parathyroid hyperplasia in our case of renal rickets together with osteoclastic resorption in the bones, is no mere fortuitous finding, but must be considered to be a part of the picture of the malady. The unusual length of time which the boy lived, more than six years after his renal inefficiency had become serious enough to produce a blood-urea value of $132 \mathrm{mgrm}$. per cent., may explain the existence of parathyroid masses large enough to ke obvious.

We suggest as an explanation of the bony changes that although the chronic renal disease occurring in renal dwarfism may cause true rachitic changes in the bones, yet that the most characteristic osseous changes seen radiographically as the honeycomb, stippled or woolly form, are due to osteoclastic resorption, the result of secondary parathyroid overactivity.

We wish to thank Dr. H. Courtney Gage for the radiograms and for his radiological report.

\section{REFERENCES.}

1. Parsons, L. G., Dis. of Children, Garrod, A. E., et al., Lond., 1929, 2nd Ed., 122.

2. Shipley, P. G., et al., Am. J. Dis. Child., Chicago, 1922, XXIII, 91.

3. Teall, C. G., Brit. J. Radiol., Lond., 1928, N.S., I, 19.

4. Brockman, E. P., Brit. J. Surg., Bristol, 1927, XIV, 634.

5. Hunter, D., Lancet, Lond., 1930, i, 1004.

6. Swart, H. A., J. Bone \& Joint Surg., Boston, 1930, XII, 876.

7. Camp, J. D., \& Ochsner, H. C., Radiology, St. Paul, 1931, XVII, 63.

8. Russell, D. S., Med. Res. Council Sp. Rep. Ser., 1929, No. 142, 149.

9. Hunter, D., Lancet, Lond., 1930, i, 950.

10. Erdheim, J., Sitzungsber. d. Kais. Akad. d. Wiss., Vienna, 1907, 3 Ab., CXVI, 311.

11. Hoffheinz, Virchows Arch. f. path. Anat. u. Physiol., Berlin, 1925, CCLVI, 705.

12. Klemperer, P., Surg. Gyn. \& Obst., Chicago, 1923, XXXVI, 11.

13. Barr, D. P., \& Bulger, H. A., Am. J. Med. Sci., Phil., 1930, CLXXIX, 447.

14. Minor, J., \& Pappenheimer, A. M., Proc. N.Y. Path. Soc., N.Y., 1921, N.S., XXI, 98.

15. Linder, G. C., \& Vadas, D. G. M., Lancet, Lond., 1931, ii, 1124.

16. Barr, D. P., \& Bulger, H. A., Loc. cit.

17. Bergstrand, H., Act. Med. Scandinav., Stockholm, 1931, LXXVI, 128.

18. Harbitz, F., J. Med. Res., Lond., 1915, XXXII, 361.

19. MacCallum, W. G., Bull. Johns Hopkins Hosp., Baltimore, 1905, XVI, 85. 